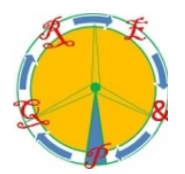

\title{
Techno-economic assessment of the use of Linear Fresnel Solar Collectors for the supply of heat in traditional fruits and vegetable processing industries in Almeria's province
}

\author{
JD. Gil ${ }^{1,2,3}$, JA. Romero Ramos ${ }^{3}$, M. Pérez García ${ }^{1,2,3}$, \\ M. Martínez Molina ${ }^{1,2,3}, J$. Ropero ${ }^{3}$, A. Rodríguez ${ }^{3}$ \\ ${ }^{1}$ CIESOL Research Center on Solar Energy, joint center UAL-CIEMAT \\ ${ }^{2}$ Automatic Control, Robotics and Mechatronics group. University of Almería \\ ${ }^{3}$ School of Engineering. University of Almería \\ University of Almería \\ Ctra. De Sacramento s/n 04120 Almeria (Spain) \\ Phone number:+0034950014140, e-mail: juandiego.gil@ual.es, jrr206@inlumine.ual.es, mperez@ual.es, \\ mmm804@ual.es, jesrm2b@gmail.com, alvaro re@icloud.com
}

\begin{abstract}
.
This study presents a techno-economic assessment of the use of Linear Fresnel Solar Collectors for the heat supply in traditional fruits and vegetable processing industries in Almeria's province. This assessment is justified by the high availability of solar radiation in the area under study, the evaluation of complementary energy self-consumption modalities, and the suitability of using local resources for the preservation and improvement of traditional productive activities. The work starts with an identification of the potential user's needs and their location in the province. Afterward, the solar radiation resources have been estimated as they constitute one of the basic inputs for sizing the proposed systems. Together with the above, representative thermal demands have been considered and different configurations of commercial Linear Fresnel Solar Collector thermal plants aimed to contribute to solarize the analyzed productive processes have been designed and the corresponding techno-economic assessment have been undertaken. Main findings advance the profitability that can be achieved with this technology, reaching, after an optimized integration of the solar plant in the industrial process, a solar fraction between 66-82\% and payback periods of the investment between 6-12 years.
\end{abstract}

Key words. Solar energy, solar fraction, process heat.

\section{Introduction}

It is well established that solar energy, thanks to the maturity and reliability of photovoltaic systems, has been playing along the years an important role in the supply of many electricity-driven demands (i.e., lighting, water, pumping, and so on) linked to the provision of social services, economic growth, and improved quality of life in isolated population settlements, farms, and other traditional productive activities [1]. Nevertheless, the use of solar energy in this context to supply heat, instead of electricity, is still a scarcely explored niche despite the existence of well-known thermal demands in microindustries devoted to cheese and milk products, traditional spirituous beverage elaboration farms, fruits, and vegetable conservation industries. One of the reasons limiting the use of solar energy for those demands is that they need to be feed by thermal fluids as air, pressurized water, steam, or oil at temperatures that are not reachable by the wide-spread flat-plate solar thermal collectors [2]. Accordingly, biomass is the only renewable option [3], so far, to conventional liquid fuels which currently constitute the main energy source of these microindustries. But the recent interest by solar companies, research centers, and technical associations in the socalled Solar Heat for Industrial Processes (SHIP) field allows accounting with many operative references on solar installations using concentrating thermal solar collectors in factories and productive nuclei despite the complex and heterogeneous nature of the projects due to the costs and operative constraints [4].

Based on the above issues, this paper aims to contribute to the justification of the implementation of SHIP facilities to the ongoing initiatives related to the use of renewable sources in traditional population settlements and industries. Specifically, a techno-economic assessment of the use of Linear Fresnel Solar Collectors, one of the existing modular and reliable options of solar concentrators, for the heat supply in traditional fruits and vegetable processing industries in Almeria's province is accomplished. By and large, the main objectives can be summarized as: i) Analyze the potential, in terms of solar irradiance, of the province of Almería for the use of said technology and locate different companies that meet the requirements for its implementation, ii) determine the demand of one of the localized industries and generate different case studies based on it to evaluate how the size of the industry and the homogeneity of demand influence the technical solution, and iii) design of a SHIP system for each of the case studies considered and economic evaluation of the different solutions. 
The paper is organized as follows: Section 2 presents the main material and methods used in the study, including an overview of the potential user's needs and locations, the case studies considered, and the tools used to carry out the design and to perform the economic evaluation. Section 3 presents and discusses the main results obtained. Finally, section 4 summarizes the main findings of this research.

\section{Material and methods}

\section{A. Overall context and solar resources}

The province of Almería is located in South-eastern Iberian Peninsula, between latitudes $37^{\circ} 52^{\prime}$ and $36^{\circ} 40^{\prime}$ and longitudes $1^{\circ} 37^{\prime}$ and $3^{\circ} 07^{\prime}$, at the eastern end of the Autonomous Community of Andalucía, in Spain. It occupies an area of $8.774 \mathrm{~km}^{2}(1.7 \%$ of the Spanish territory), with $219 \mathrm{~km}$ of coastline. This province is characterized by the high availability of solar resources.

The main economic activity in Almería's province is intensive agriculture, which is concentrated in the southern coastal strip and constitutes an extremely productive and high-income area. This has meant that the inland areas of the province are becoming depopulated and staying outside the main lines of access to energy. Some official initiatives are being tackled aiming to preserve these inland population settlements by means of the promotion of some added value activities such as sustainable tourism, traditional and ecological cultivation, and food processing. In this study, at least, 10 small companies related to canning and traditional crops processing have been located [5] (Fig. 1), all of them characterized by their remoteness from main energy supply lines, their small range demand, and the coincidence of using fossil fuels as the main thermal energy source.

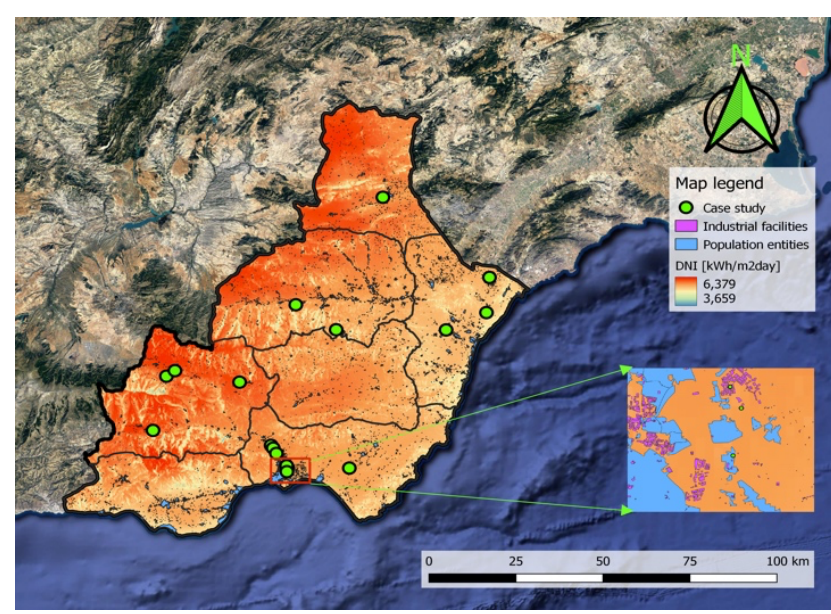

Fig. 1. Almería's province map, own elaboration. The yearly direct normal irradiation data were obtained from [6], the population settlements and industry parks from [7], and the location of the traditional food preserving industries from [5].

Regarding solar resource, as concentrating technologies are considered in this study, Direct Normal Irradiation (DNI) estimations, instead of normally available global values of Global Horizontal Irradiation (GHI), must be assessed. DNI, which in fact is the more relevant component of GHI, is a site-dependent magnitude because of the influence of local factors as the altitude, the topography, the local atmosphere composition, and the microclimate. DNI variability in Almería's province has been analyzed based on a geographical clustering according to the officially established cultivation regions [5]. DNI ranges from more than $2200 \mathrm{kWh} / \mathrm{m}^{2} \mathrm{y}$ in Los Vélez, Alto Almanzora, Río Nacimiento - Alto Andarax regions (higher locations in the map of Fig. 1) to 1950 $\mathrm{kWh} / \mathrm{m}^{2} \mathrm{y}$ in Campo de Dalías region. In general, the annual DNI is higher in the western regions between a $7 \%$ and $10 \%$ coefficient of variation compared to the eastern regions. The reader is referred to Fig. 2 to observe the annual DNI variation in the different cultivation areas.

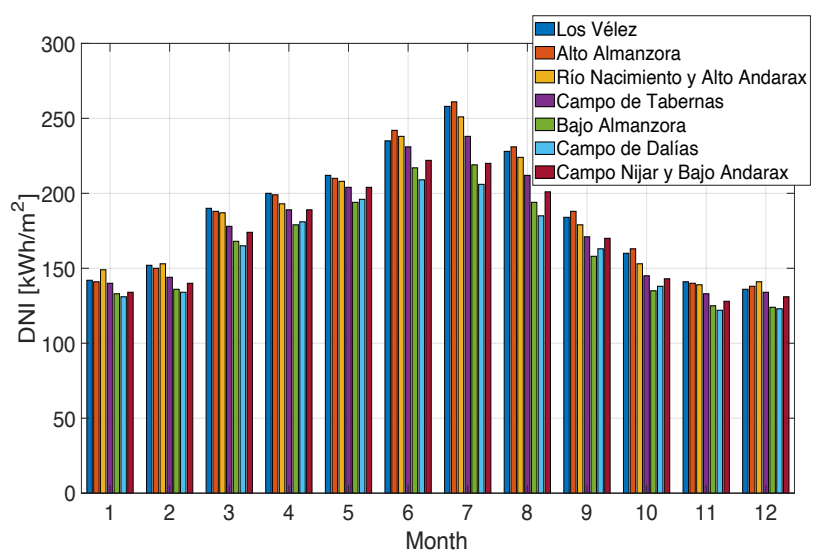

Fig. 2. Monthly distribution of DNI irradiation for the cultivation regions of the province of Almería [6].

\section{B. Case studies of preserved vegetable industrial plants}

A case study based on a real and representative preserved vegetable facility, based on preliminary information cross-checking, has been used as a reference. The facility is placed in a rural zone in one of the favourable abovementioned regions of Almería's province. It has a total annual production of around $91 \mathrm{t}$ (specific data are not used for confidentiality reasons). Its products are mainly related to the tomato, producing fried tomato, grated tomato, and gazpacho among others, and it works with a single day shift with stops at weekends. The total annual thermal demand of the industry is $101510 \mathrm{kWh}, 64 \%$ of those are directly consumed by the process while the remaining are thermal losses in the distribution system and boiler efficiency. This thermal energy is supplied by a fuel oil boiler, being the required process temperature $160^{\circ} \mathrm{C}$ whereas the return temperature $90^{\circ} \mathrm{C}$.

The actual annual thermal energy demand profile is presented in Fig. 3 and it was evaluated on an hourly time basis. Note that the demand profile varies for each month of the year as a function of the labor days and the kinds of products being processed.

Apart from this nominal case, several additional case studies were generated based on it to evaluate different distributions of the demand profile and different industry sizes. Thus, case study 2 was generated considering that the industry works at maximum power during the entire year (see Fig. 4). The total annual thermal demand of this 
case is $180250 \mathrm{kWh}$. Them, for case studies 3 and 4, an industry with a double production, i.e., $181 \mathrm{t}$, was considered. So that case study 3 corresponds to the same profile as case study 1 but with the twice of demand, and case 4 to the same profile as case 2 but also with twice demand. The total thermal energy demand for these cases is 203010 and $360510 \mathrm{kWh}$ respectively.

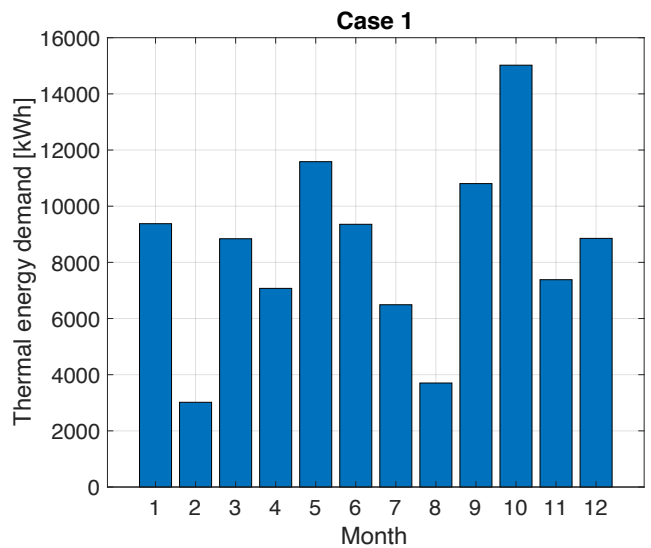

Fig. 3. Annual thermal demand profile. Case study 1.

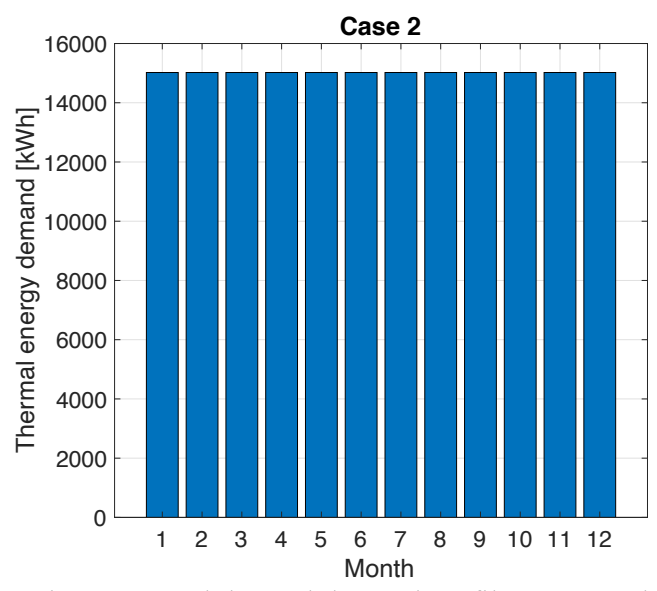

Fig. 4. Annual thermal demand profile. Case study 2.

\section{Linear Fresnel Collector}

Solar concentrating technology has been proven as a very suitable way to provide heat to thermo-mechanical cycles operating above $400{ }^{\circ} \mathrm{C}$ in power plants. Besides, it is, so far, the more dispatchable renewable source option thanks to the demonstrated reliability of the heat storage in molten salts tanks. In this context, recent developments of modular and small-sized concentrating solar thermal collectors allow also coping with other medium-range thermal demands from $100{ }^{\circ} \mathrm{C}$ to $250{ }^{\circ} \mathrm{C}$ [8] for industries and end-users having operational constraints for solar energy application at small-scale and non-uniform heat demands that difficult the options to find the size and integration of standard systems.

Linear Fresnel is one of the two available solar collectors' technologies, along with low aperture parabolic trough, aiming to tackle the above solar applications [9]. Parabolic trough collectors present a better performance in terms of power generation. However, it has been proven how Linear Fresnel collectors can improve the exergy efficiency in comparison with the parabolic trough in some applications [10]. Besides, Linear Fresnel collectors require less space and operation and maintenance labors [9]. Fresnel collectors consist of a set of rows of long flat or slightly curved ground-mounted mirrors, being the absorber tube located above the mirrors and remaining fixed to a structure while reflective rows below track de sun. Discontinuous reflectors lead to lower performance but also to lower costs and easier assembly and roof integration. In this study, the specifications of a Fresnel collector designed and manufactured by the Spanish company SOLATOM are used as a base case. In addition to the above advantages, this collector is distributed in the form of deployable units of $15 \mathrm{~kW}$ thermal nominal power, easing a modular installation design and quick onsite mounting (see Fig. 5).

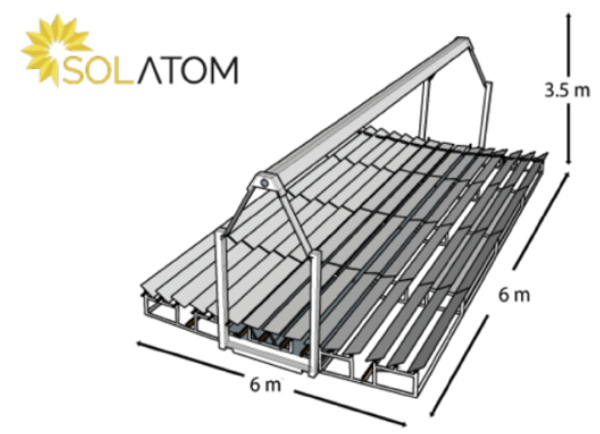

Fig. 5. SOLATOM linear Fresnel characteristics.

\section{ReSSSPI software}

ReSSSPI [11] is a specific front-end developed by the SOLATOM company that serves as a web calculator for SOLATOM collectors. This software, based on an opensource code (PYTHON 3), can estimate both the systems' energy performance and the financial aspects of the application at hand using the information provided by the users through an online form. This information basically consists of the industry sector, the industry size, the type of fossil fuel currently used, the annual thermal demand, and the location. With this information, ReSSSPI can perform automatic simulations or, additionally, users can make their own by providing the integration scheme, the number of linear Fresnel collectors, and the capacity of the storage system if the integration scheme includes it. Some information about the process could be also added as temperatures or heat transfer medium.

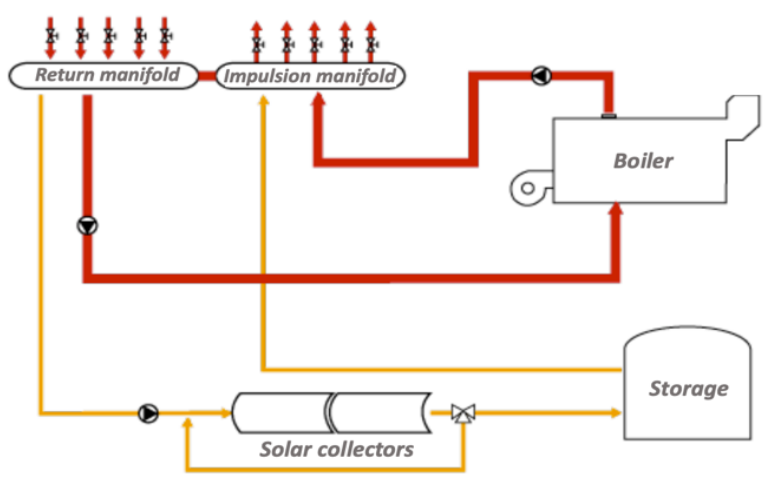

Fig. 6. Integration scheme used in the ReSSSPI software. 
In this paper, the manual option was used to study technoeconomic aspects considering different solar field sizes. In all the simulations, the integration scheme adopted was the "SL_L_PS" (see Fig. 6) in line with those reported in the IEA SHC Task 49 - Integration Guideline - Feb 2015, using as heat transfer medium overheated water and varying the size of the storage system according to the solar field size.

\section{E. Techno-economic metrics}

Solar fraction was used as a performance metric in this work. This concept relates the amount of energy provided by the solar field and the total energy required by the process, which is calculated as follows:

$$
S F[-]=\frac{Q_{\text {sol }}}{Q_{\text {load }}}
$$

where $S F$ is referred to the solar fraction, $Q_{S o l}$ is the energy provided by the solar field, and $Q_{\text {load }}$ the thermal demand of the industry [kWh].

Furthermore, to evaluate the economic viability of the integration of the solar heat system in the different cases studies, the cash flow metric was used:

$$
\begin{gathered}
\text { Cash flow }[€]=C_{\text {invest }}+\sum_{j=1}^{N} \text { Solar savings }(j) \\
-C_{m}(j)
\end{gathered}
$$

where $C_{\text {invest }}$ are the investment cost of the facility [€], and $C_{m}$ are the maintenance cost $(120 € /$ collector $)$ that are incremented each year by $2.5 \%$. Both the maintenance costs and the increasing factor were obtained from the ReSSSPI software [11] (www.ressspi.com). Solar savings are the economic savings obtained with the solar system when compared to the cost of the conventional power device of the industry (i.e., fuel oil boiler). For each year $j$, these savings were calculated as follows:

Solar savings $(j)[€]=\frac{Q_{\text {sol }} \cdot(1-s)^{j}}{\eta_{\text {boiler }}} \cdot C_{\text {fuel }}(j)$,

where $\eta_{\text {boiler }}$ is the boiler efficiency (0.8 [12]) and $C_{\text {fuel }}$ is the fuel price $(0.053 € / \mathrm{kWh}[13]) . s$ is the annual degradation factor of the solar field, fixed at $0.5 \%$ [14]. Also, the fuel prize was increased by $3.5 \%$ each year [14].

\section{Results and discussion}

\section{A. Simulation set-up}

Fig. 7 shows how the simulations were performed. First, ReSSSPI software was used to obtain technic and economic aspects of the integration of the solar system in each of the case studies. To each case, different solar field sizes and storage tank volumes were tested in ReSSSPI which are summarized in Tab. I. The investment cost of each configuration is also provided. It should be remarked that for case studies 1 and 2 only the configurations from 1 to 9 were tested, as the rest of the configurations resulted in oversized systems, while for cases 3 and 4 all the configurations were tested.

Later on, all the results were collected and exported to MATLAB software where the long-term economic study was carried out. This study was performed using 3D response surfaces representing the cash flow as a function of the solar fraction (which is directly related to each of the solar field's configurations reported in Tab. I) and the time horizon, i.e., the lifetime of the facility.

\section{Step 1: ReSSSPI simulation}

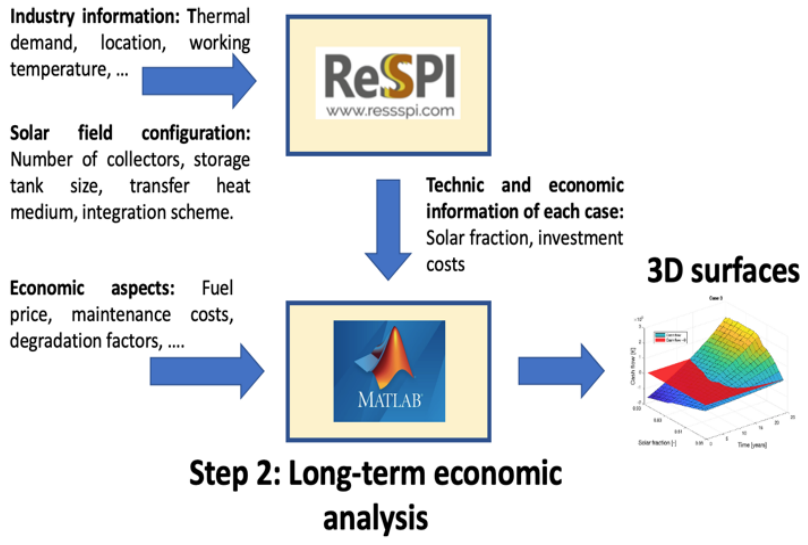

Fig. 7. Schematic diagram showing how the simulations were carried out.

\section{B. Techno-economic analysis}

Figs. 8-11 show the results obtained for each of the case studies. It must be remarked that in all of them, the surface with the cash flow equal to zero was included so that the cut among the cash flow surface and the aforementioned determines the year of the return of the investment. Moreover, the better result obtained for each of the case studies is presented in Tab. II. In this table, only the number of collectors is included, but this number is directly related to the configurations (i.e., storage tank capacity, solar field size, and investment costs) reported in Tab. II.

Overall, the better solar fraction for all the cases varies between 0.66 and 0.82 . For instance, in case study 1 , it can be observed (see Fig. 8) how low (i.e., less than 0.3) and high (i.e., more than 0.8 ) solar fractions resulted in investment costs with large return periods, being in some cases equal to the lifetime of the facility (i.e., 25 years). For solar fractions between 0.65 and 0.75 the results in economic terms were very similar with return periods between 12 and 13 years. In case study 2, the behavior was also comparable for low solar fractions (see Fig. 9). However, it can be seen how the return period was reasonable for high solar fractions (see the cut line among the two surfaces in Fig. 9). This was caused since the demand profile of this case study was well scattered among all the months. This also benefited the economic results providing a lower return period, 7 years. In case studies 3 and 4, where the demand was twice, the 
behavior in terms of the solar fraction was similar to case 1 and 2 respectively (see Fig. 9 and 10). Nevertheless, the increment in the demand notably improved the return period of the investment. In this way, the better results for cases 3 and 4 were obtained with a solar fraction of 0.70 and 0.66 providing a return period of the investment of 8 and 6 years respectively (see Table II).

Tab. I. Solar field configurations simulated in ReSSSPI and investment cost of each configuration.

\begin{tabular}{|c|c|c|c|c|c|c|c|c|c|c|c|c|c|c|c|}
\hline $\begin{array}{c}\text { Number } \\
\text { of } \\
\text { collectors }\end{array}$ & 1 & 2 & 3 & 4 & 5 & 6 & 7 & 8 & 9 & 10 & 11 & 12 & 13 & 14 & 15 \\
\hline $\begin{array}{c}\text { Solar } \\
\text { field size } \\
{\left[\mathrm{m}^{2}\right]}\end{array}$ & 39 & 79 & 118 & 158 & 198 & 237 & 277 & 316 & 356 & 396 & 435 & 475 & 514 & 554 & 594 \\
\hline $\begin{array}{c}\text { Storage } \\
\text { tank } \\
\text { volume } \\
{\left[\mathrm{m}^{3}\right]}\end{array}$ & 2 & 3 & 3 & 4 & 4 & 6 & 6 & 9 & 10 & 10 & 10 & 11 & 12 & 13 & 13 \\
\hline $\begin{array}{c}\text { Investm- } \\
\text { ent costs } \\
{[k \epsilon]}\end{array}$ & 36.8 & 49.1 & 59.2 & 69.3 & 78.3 & 88.1 & 96.7 & 106.7 & 114.9 & 131.5 & 139.5 & 147.7 & 155.9 & 163.7 & 171.1 \\
\hline
\end{tabular}

Tab. II. Results.

\begin{tabular}{|l|c|c|c|}
\hline & $\begin{array}{c}\text { Number of } \\
\text { collectors }\end{array}$ & $\begin{array}{c}\text { Solar } \\
\text { fraction } \\
\text { [-] }\end{array}$ & $\begin{array}{c}\text { Return } \\
\text { year }\end{array}$ \\
\hline Case 1 & 4 & 0.69 & 12 \\
\hline Case 2 & 7 & 0.82 & 7 \\
\hline Case 3 & 7 & 0.70 & 8 \\
\hline Case 4 & 9 & 0.66 & 6 \\
\hline
\end{tabular}

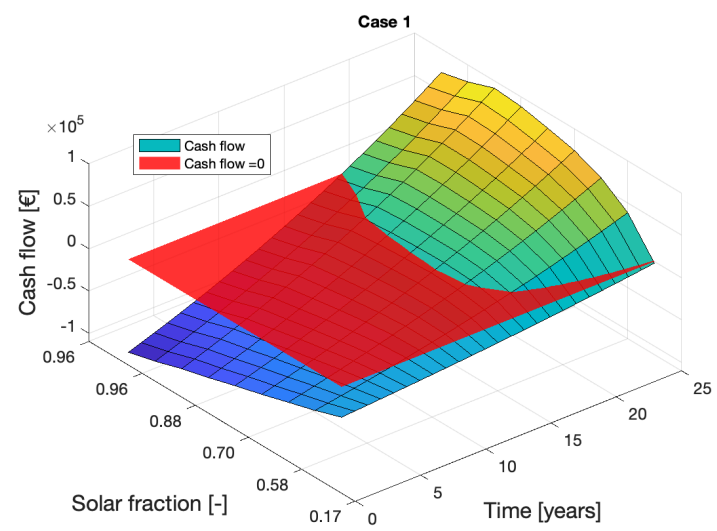

Fig. 8. Results case study 1.

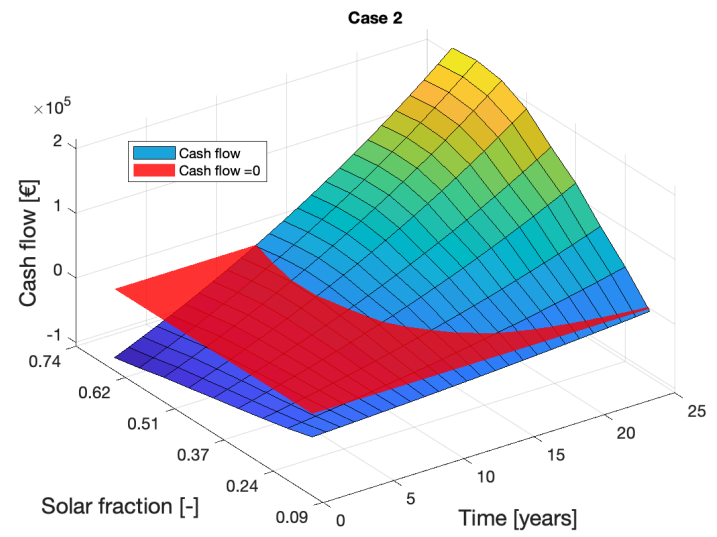

Fig. 9. Results case study 2.

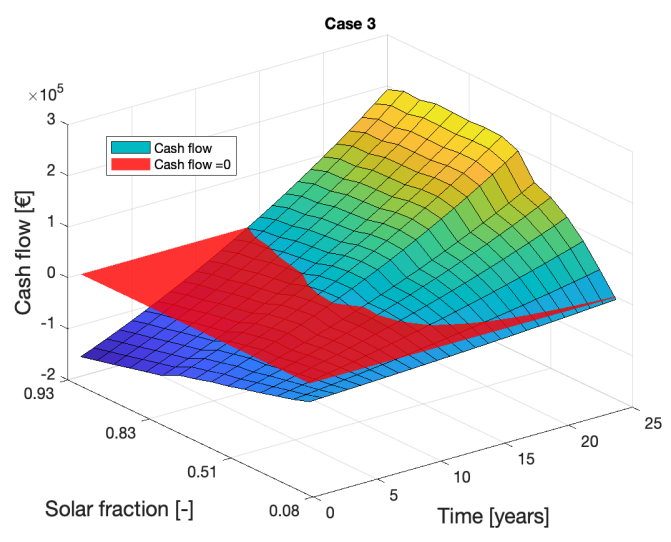

Fig. 10. Results case study 3.

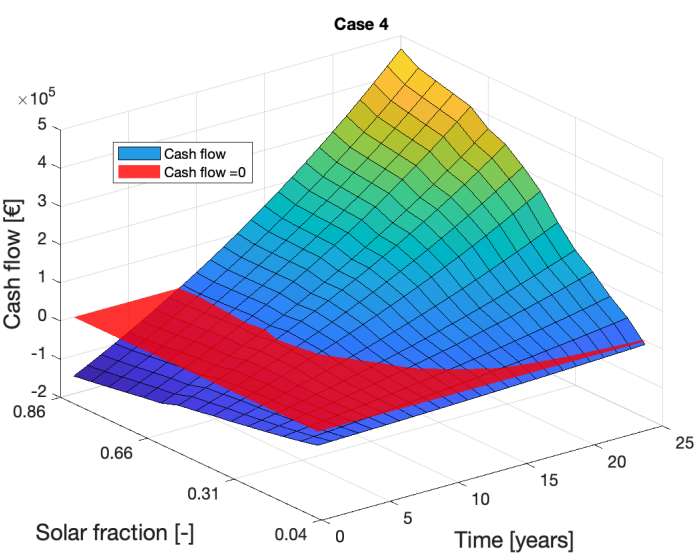

Fig. 11. Results case study 4. 


\section{Conclusions}

This paper presents the results of a techno-economic assessment of the potential use of solar concentrating technologies for feeding the heat demand of traditional fruits and vegetable processing industries in Almeria's province. The preliminary results show the adequacy of the proposed SHIP solutions in all the case studies considered. The main findings that can be drawn from the results are:

- Regarding the technical metrics, a solar fraction of around $66-82 \%$, after optimized integration of the solar plant according to the industry thermal load, could be reached for all case studies. It was observed how, in general, the optimal solar fraction was lower for industries with large demands (case studies 3 and 4).

- Concerning economic terms, all the case studies resulted in payback periods of around 6 to 12 years. For cases with heterogeneous demands, i.e., case studies 1 and 3, the payback period was greater, 12 and 8 years respectively, than for cases with homogeneous demands, which was found 7 and 6 years for case studies 2 and 4 respectively. This evidenced how the homogeneity of the demand is a key factor in the economic performance of the SHIP system for the area and industries under study.

- Similarly, the size of the industry was also found to be a fundamental aspect influencing the payback time. The results showed how, for industries with higher demand, the payback period was less, 8 and 6 years for case studies 3 and 4 respectively, than for industries with the same demand profile but with half of the demand, which was found 12 and 7 for case studies 1 and 2 respectively.

Moreover, it should be noted that the proposed design method is not only valid for heat for industrial processes, but it can be also applied to other applications like district heating.

\section{Acknowledgement}

This work has been carried out as part of the project entitled "MICRORREDES PARA EL AUTOABASTECIMIENTO SOLAR DE ENTORNOS PRODUCTIVOS AISLADOS (MICROPROD-SOLAR)" funded by the International Joint Programming initiative of the State Research Agency of the Spanish Government, grant PCI2019-103378 and by the Iberoamerican Program for Science and Technology for the Development (CYTED).

\section{References}

1. Ramirez, P., Mendoza, P., Valencia, F., León, G., Cornejo, L., Montedonico, M. and JiménezEstévez, G. Sustainable development through the use of solar energy for productive processes: The Ayllu Solar Project. In IEEE Global Humanitarian Technology Conference (IEEE, 2017), pp. 1-8.

2. Rojas, D., Beermann, J., Klein, S. A., \& Reindl, D. T. (2008). Thermal performance testing of flat-plate collectors. Solar Energy, 82(8), 746757.

3. Bajwa, D. S., Peterson, T., Sharma, N., Shojaeiarani, J., \& Bajwa, S. G. (2018). A review of densified solid biomass for energy production. Renewable and Sustainable Energy Reviews, 96, 296-305.

4. Farjana, S. H., Huda, N., Mahmud, M. P., \& Saidur, R. (2018). Solar process heat in industrial systems-A global review. Renewable and Sustainable Energy Reviews, 82, 22702286.

5. GRIA, 2021. Registro de industrias agroalimentarias. Obtained from: http://www.juntadeandalucia.es/agriculturaypesc a/gria/ (accessed on 20 March 2021).

6. World Bank Group, 2019. Global Solar Atlas. Obtained from: https://globalsolaratlas.info/map (accessed on 20 March 2021).

7. CNIG, 2021. Centro nacional de información geográfica. Obtained from: http://centrodedescargas.cnig.es/CentroDescarga s/index.jsp\# (accessed on 20 March 2021).

8. Naik, H., Baredar, P., \& Kumar, A. (2017). Medium temperature application of concentrated solar thermal technology: Indian perspective. Renewable and Sustainable Energy Reviews, 76, 369-378.

9. Zhu, G., Wendelin, T., Wagner, M. J., \& Kutscher, C. (2014). History, current state, and future of linear Fresnel concentrating solar collectors. Solar Energy, 103, 639-652.

10. López, J. C., Escobar, A., Cárdenas, D. A., \& Restrepo, Á. (2021). Parabolic trough or linear fresnel solar collectors? An exergy comparison of a solar-assisted sugarcane cogeneration power plant. Renewable Energy, 165, 139-150.

11. Frasquet, M., Bannenberg, J., Vila, Y. N., \& Silva, M. (2018). RESSSPI: The Network of Simulated Solar Systems for Industrial Processes. In Proceedings of the ISES EuroSun 2018 Conference (pp. 239-247). International Solar Energy Society.

12. Shah, S., \& Adhyaru, D. M. (2011, December). Boiler efficiency analysis using direct method. In 2011 Nirma University International Conference on Engineering (pp. 1-5). IEEE.

13. IDAE. Informe de precios energéticos: Combustibles y carburantes. Obtained from: https://www.idae.es/sites/default/files/estudios_i nformes_y estadisticas/combustibles_y carbura ntes jul 2018.pdf (accessed on 20 March 2021).

14. Cabeza, L. F., Galindo, E., Prieto, C., Barreneche, C., \& Fernández, A. I. (2015). Key performance indicators in thermal energy storage: Survey and assessment. Renewable Energy, 83, 820-827. 